\title{
Da Vinci's ascent: Continually broadening the scope of robotic thoracic surgery
}

\author{
Laurence P. Diggs, MD, and R. Taylor Ripley, MD
}

\author{
From the Thoracic and Oncologic Surgery Branch, Center for Cancer Research, National Cancer Institute, Na- \\ tional Institutes of Health, Bethesda, Md. \\ Disclosures: Authors have nothing to disclose with regard to commercial support. \\ Received for publication Feb 7, 2018; accepted for publication Feb 10, 2018; available ahead of print March 16 \\ 2018. \\ Address for reprints: R. Taylor Ripley, MD, Thoracic and GI Oncology Branch, CCR/NCI, Building 10, 4-3952, \\ 10 Center Drive, MSC 1201, Bethesda, MD 20892-1201 (E-mail: Taylor.Ripley@nih.gov). \\ J Thorac Cardiovasc Surg 2018;156:e133-4 \\ $0022-5223 / \$ 36.00$ \\ Copyright (C) 2018 by The American Association for Thoracic Surgery \\ https://doi.org/10.1016/j.jtcvs.2018.02.028
}

Coined nearly 100 years ago, ${ }^{1,2}$ the term robot is now virtually ubiquitous. Machine-assisted task completion has become widespread and often indispensable. With robots percolating into most technological advances, medicine is no exception. Although the intravenous infusion pump and the mechanical ventilator were accepted unquestioningly, diagnosis-making software and robots capable of remotely performing surgery have been the subjects of controversy. ${ }^{3,4}$ Since its inception 30 years ago, robotically assisted surgery (RAS) has seen an impressive rise in popularity and applicability, ranging from urologic and gynecologic surgery to microsurgery and cardiac surgery.

In the featured article, Hodges and colleagues ${ }^{5}$ describe a case of symptomatic pleural myopericytoma successfully managed with RAS. Derived from perivascular myoid cells, myopericytomas are rare, typically benign subcutaneous tumors usually located on the extremities, with only a few case reports describing intrathoracic disease. ${ }^{5-7}$ In this case, the patient's symptoms prompted an elective surgical resection. Given the reported success of robotically assisted thoracic surgery (RATS) ${ }^{8}$ as well as the anatomic location of the tumor abutting the brachial plexus and subclavian artery, the authors felt that the dexterity and 3-dimensional viewing capability afforded by RATS would facilitate periadventitial dissection. The patient underwent successful resection without neurovascular injury and had an uncomplicated postoperative course.

Hogdes and colleagues ${ }^{5}$ use of RAS to resect a complex pleural mass exemplifies the benefits of adding robotics to the thoracic surgeon's armamentarium in addition to the ever-increasing applicability of this technology. The literature on RAS for pleural tumors is sparse, but the featured case demonstrates that, in well-trained hands, RAS should be considered a reasonable alternative to video-assisted thoracic surgery (VATS) or thoracotomy.

When compared with open surgery, minimally invasive thoracic surgery has demonstrated a significant reduction in morbidity, postoperative pain, and hospital stay. ${ }^{4,8}$

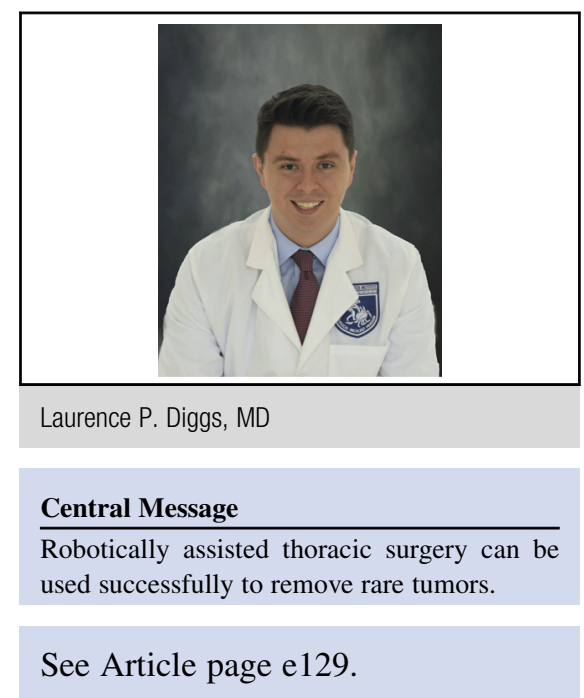

However, comparisons between VATS and RATS have not determined a clear winner. Himidan and $\mathrm{Kim}^{9}$ describe how surgery is being transformed by new technologies, both in information technology and in surgical tool development. The need for new tools to perform more complex procedures is undeniable, but the use of these tools is likely to be predicated on the outcomes with which they are associated. Yamashita and colleagues ${ }^{4}$ express concern that RAS carries a heavy cost burden without providing significant outcomes-based advantages over VATS. As seen in the featured article, experienced surgeons describe an advantage to the dexterity provided by the robot. They suggest that this attribute, though costly in the operating room, will translate into fewer complications and better outcomes. $^{8}$ While these technical gains should be taken into consideration, no randomized trial demonstrating an advantage of RATS over VATS has been published to date. ${ }^{3,4}$ Such studies may prove difficult to implement but would likely play a key role in justifying the use of a costly technology in a time when health care budgets are becoming increasingly restrictive.

\section{References}

1. Satava RM. Surgical robotics: the early chronicles: a personal historical perspective. Surg Laparosc Endosc Percutan Tech. 2002;12:6-16.

2. Leal Ghezzi T, Campos Corleta O. 30 years of robotic surgery. World J Surg. 2016 40:2550-7.

3. De Wilde RL, Herrmann A. Robotic surgery_advance or gimmick? Best Pract Res Clin Obstet Gynaecol. 2013;27:457-69.

4. Yamashita S, Yoshida Y, Iwasaki A. Robotic surgery for thoracic disease. Ann Thorac Cardiovasc Surg. 2016;22:1-5. 
5. Hodges K, Zou Y, Everett A, Murthy S, Ahmad U. Pleural myopericytoma: a rare neoplasm in a difficult location. J Thorac Cardiovasc Surg. 2018;156: e129-31.

6. Dray MS, McCarthy SW, Palmer AA, Bonar SF, Stalley PD, Marjoniemi V, et al. Myopericytoma: a unifying term for a spectrum of tumours that show overlapping features with myofibroma. A review of 14 cases. J Clin Pathol. 2006;59:67-73.
7. Edgecombe A, Peterson RA, Shamji FM, Commons S, Sekhon H, Gomes MM. Myopericytoma: a pleural-based spindle cell neoplasm off the beaten path. Int J Surg Pathol. 2011;19:247-51.

8. Kumar A, Asaf BB. Robotic thoracic surgery: the state of the art. J Minim Access Surg. 2015;11:60-7.

9. Himidan S, Kim P. The evolving identity, capacity, and capability of the future surgeon. Semin Pediatr Surg. 2015;24:145-9. 